\title{
Narrativas de mulheres lésbicas sobre as vivências no cotidiano e no período escolar
}

\author{
Ana Laura Almeida' (iD) 0000-0002-661 1-2879 \\ Rosângela Rodrigues Soares ${ }^{2}$ (iD 0000-0001-6599-1608 \\ 'Universidade Federal do Rio Grande do Sul, Instituto de Biociências, Porto Alegre, RS, \\ Brasil. 90040-060 - comunicacaoib@ufrgs.br \\ 2Universidade Federal do Rio Grande do Sul, Faculdade de Educação, Departamento \\ de Ensino e Currículo, Porto Alegre, RS, Brasil. 90040-060 - dec@ufrgs.br
}

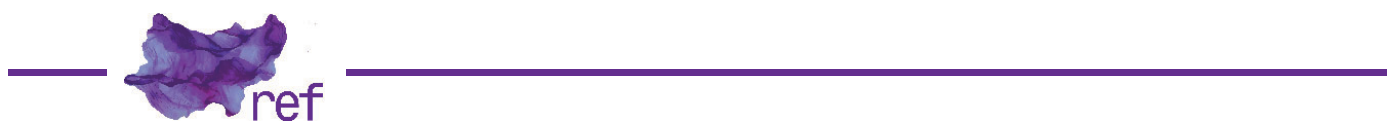

Resumo: Questões relativas à LGBTfobia e ao preconceito de gênero são comuns na escola e nos currículos escolares. Por meio de entrevistas narrativas com sete mulheres lésbicas oriundas tanto da rede pública quanto da rede privada de educação, este artigo buscou mostrar a percepção delas sobre essas questões. A partir da análise das entrevistas, o trabalho teve como objetivos traçar as especificidades e as sutilezas da construção das identidades no espaço escolar, bem como mostrar a representatividade sexual nos conteúdos escolares. O reconhecimento da identidade homoafetiva foi atravessado por violências de gênero que vão ao encontro de questões ligadas à lesbofobia. O currículo escolar, evidenciando a heteronormatividade pelo viés da reprodução de Infecções Sexualmente Transmissíveis (IST), posiciona a escola como reprodutora de normas com relação a questões de gênero e sexualidade.

Palavras-chave: sexualidade na escola; relações de gênero; LGBTfobia; currículo.

Narratives of Lesbian Women in the School and in Daily Routine

Abstract: LGBTphobia and gender bias issues are common in school and school curricula. Through narrative interviews with seven lesbian women, coming from both public and private education, this article aimed to show their perception of these issues. From the analysis of the interviews, the article goals were to trace the specificities and subtleties of the construction of identities in the school space, as well as show the sexual representativeness in the school subjects. The recognition of homoaffective identity has been crossed by gender-based violence that meets the lesbophobia issues. The school curriculum, highlighting the heteronormativity by the bias of STIs reproduction, sets the school as a reproducer of norms regarding gender and sexuality issues.

Keywords: Sexuality at school; Gender relations; LGBTphobia; Curriculum.

\section{Introdução}

A instituição escolaré permeada por diversos aspectos sociais que justificam a essencialidade do seu papel na sociedade: é onde são recebidas as filhas e filhos de pais e mães trabalhadoras, assim como também é a instituição que representa o acesso e a universalização da educação, previstas em lei, independentemente da classe social (Lúcia PADILHA, 2010), embora, na prática, o acesso e a qualidade da permanência ainda careçam de garantias. Por conta desse papel universal, o público que é recebido na escola reflete transformações sociais que ocorrem na sociedade, tendo a escola, hoje, como desafio, o acolhimento efetivo da diversidade social, sem distinção de gênero, etnia ou orientação sexual. No entanto, percebemos que a instituição escolar possui inúmeras falhas no percurso da universalização do acesso e da garantia da permanência, 
tanto no sentido estrutural quanto no que tange ao respeito e à inclusão da diversidade humana. Para Guacira Louro (201 1), a escola produz diferenças, reproduzindo mecanismos de segregação, de ordenação, de hierarquização, sendo, ainda hoje, diferente para pessoas pobres e ricas, negras e brancas, meninas e meninos.

As reproduções às quais a autora se refere estão atreladas a processos de normatização social. Ou seja, em nossa sociedade, há uma norma que parece se estabelecer historicamente, relacionada ao homem branco, heterossexual, de classe média urbana e cristão, e que passa a ser a referência que não precisa mais ser nomeada, conferindo o status de 'outros' a todas as demais identidades que estão em desacordo com esse padrão. Assim, mulheres são consideradas 'o segundo sexo', e gays e lésbicas são vistos como desviantes da norma heterossexual, se considerarmos o gênero e a sexualidade.

Esses processos adentram e se expressam no espaço escolar, residindo, aí, as limitações dessa instituição em lidar com a diversidade de gênero e sexual. Na escola, é visível a diferença no trato entre meninos e meninas, sendo aceitos, por exemplo, da parte dos meninos, comportamentos como a agressividade, ao passo que, para as meninas, o esperado é a docilidade. Embora alguns aspectos tenham evoluído, existem espaços onde essa diferença persiste, havendo, inclusive, separação de gêneros em algumas situações - como nas aulas de Educação Física, em que meninos, tradicionalmente, jogam futebol e as meninas praticam outros esportes. Helena Altmann, Eliana Ayoub e Sílvia Amaral (2011) destacam que, por muito tempo, as ditas diferenças em habilidades esportivas entre meninas e meninos foram sustentadas por questões biológicas consideradas inatas de cada sexo. Embora as pesquisas sobre o corpo e a sexualidade tenham demonstrado que diferenças sexuais são inscritas histórica e socialmente por meio da produção de saberes que nos constrói homens e mulheres (Thomas LAQUEUR, 2001) e pelas distintas formas de se educar os corpos masculinos e femininos, práticas segregadoras ainda prevalecem nas aulas de Educação Física.

A obediência à heteronormatividade também é forte e vigente dentro da escola. Conforme a Pesquisa Nacional sobre Estudantes LGBTs ${ }^{1}$ e o Ambiente Escolar, realizada no Brasil pela Associação Brasileira de Lésbicas, Gays, Bissexuais, Travestis e Transexuais (ABGLT), 73\% das(Os) jovens entrevistadas(os) foram agredidas(os) verbalmente por causa da sua orientação sexual. Apenas 8,3\% das(os) estudantes afirmaram que o regulamento da escola tinha alguma disposição sobre orientação sexual, identidade/expressão de gênero, ou ambas (ABGLT, 2016). Assim, as escolas nem sempre conseguem ter um bom convívio de respeito e solidariedade a pessoas LGBTs, seja por causa da lógica heteronormativa instaurada nas práticas de ensino, seja pela perda do referencial de laicidade. Esse cenário favorece a prática de bulliyng LGBTfóbico, que vai desde piadas e comentários até violência física, produzindo vulnerabilidades sociais e psicológicas, submetendo essas pessoas à experiência da injúria (Wiliam PERES, 2011 ) e tornando essas(es) jovens alvos de marcações sociais de diferença que despotencializam a existência de seus corpos. Não raramente, a relação entre homossexuais e a escola é permeada por sentimentos de angústia, desconfiança e solidão, sendo relatados, inclusive, casos de convivência passiva de professoras(es) e gestoras(es) com a violência de cunho LGBTfóbico (Vagner PRADO; Arilda RIBEIRO, 2015). No debate sobre a LGBTfobia, é importante, também, pontuar o conceito de lesbofobia, que é o preconceito específico contra mulheres homossexuais, primeiramente para especificar a qual segmento da população LGBT esta pesquisa está se referindo, mas também para especificar que mulheres lésbicas trazem consigo um duplo menosprezo: por serem mulheres e por serem homossexuais, acumulando discriminações relacionadas ao gênero e à sexualidade (Daniel BORILLO, 2009).

A questão do currículo também é peça-chave para se entender como a diversidade sexual é invisibilizada e silenciada dentro da escola. Patrícia Balestrin e Rosângela Soares (2015) trazem uma visão do currículo concebido como práticas, saberes, sensações, concepções, percepções, representações partilhadas e vivenciadas no espaço escolar, produzindo um jeito de conhecer e apontando o que é e o que não é legítimo de ser aprendido. A inclusão de questões de gênero e sexualidade na escola está prevista nos Parâmetros Curriculares Nacionais (PCN), nos quais a temática 'orientação sexual' é apontada como um dos temas transversais a serem abordados tanto na programação oficial das aulas quanto na extraprogramação, toda vez que o tema surgir no contexto escolar (BRASIL, 1997). No entanto, cabe às escolas a garantia dos espaços de discussão e ações pedagógicas comprometidas com questões de gênero e sexualidade, através dos Projetos Político-Pedagógicos (BALESTRIN; SOARES, 2015).

Graciela Morgade (2015) aponta a área das Ciências Biológicas como 'proprietária histórica' da educação para a sexualidade, a partir do ensino do aparelho reprodutor, numa abordagem que acaba se restringindo à anatomia, fisiologia, gravidez e doenças, temáticas que, sozinhas, não garantem a efetividade em contemplar toda a gama de identidades de gênero

${ }^{1}$ A sigla LGBT refere-se às pessoas lésbicas, gays, bissexuais e transgêneros. Essa sigla, embora não contemple a totalidade das identidades sexuais e de gênero, será utilizada ao longo do trabalho para evitar o uso de siglas com muitas letras e facilitar a fluidez da leitura. 
e orientações sexuais que estão dentro da escola, tampouco contribuem para uma educação comprometida com a promoção das igualdades. Os currículos são impregnados de matrizes normativas que se refletem em rejeição da diversidade sexual e de tudo o que foge do padrão branco heteronormativo, alimentando a misoginia, a homofobia e o preconceito racial (Rogério JUNQUEIRA, 2010). Assim, a LGBTfobia não é somente consentida como também é ensinada no currículo, a partir de representações sociais que tornam a escola um espaço de construção de discriminações e de silenciamento de expressões não hegemônicas (PRADO; RIBEIRO, 2015).

Para além das pesquisas acadêmicas, outro método efetivo para se ter uma noção aproximada dessas questões reside no simples diálogo e na escuta atenta da trajetória e vivência de uma pessoa LGBT. O pertencimento a uma dita minoria social, no geral, costuma ser um fator-chave para se estar sujeita(o) aos diversos mecanismos opressivos e invisibilizantes de identidades consideradas desviantes do padrão, e é aí que se encontra a principal motivação e justificativa para este trabalho. O desejo de dar voz às histórias de pessoas LGBTs, mais especificamente de mulheres homossexuais, e de construir narrativas que permitam perceber o quanto os preconceitos sociais adentram os muros da escola se configurou como o principal objetivo desta pesquisa. A partir dos relatos, o trabalho teve como objetivos traçar as especificidades e as sutilezas da construção das identidades no espaço escolar e durante o período de frequência à escola, bem como mostrar como a representatividade sexual nos conteúdos escolares é percebida pelas mulheres lésbicas.

\section{Metodologia}

\section{A pesquisa e as análises}

Para a realização do trabalho, foi conduzida uma pesquisa com entrevistas narrativas. A entrevista narrativa tem como objetivo obter relatos a partir de memórias de fatos vividos no passado, reinterpretados e ressignificados a partir de experiências novas e de percepções atuais (Sandra ANDRADE, 2012). Assim, a vantagem em utilizar memórias passadas de entrevistadas que já não frequentam mais o cotidiano escolar é que as atuais percepções das narradoras possibilitam que sejam dados novos olhares e sentidos àquilo que foi vivido no passado, possibilitando que sejam identificadas situações-chave cujos significados possam ter passado despercebidos quando ocorreram.

As entrevistas foram gravadas e transcritas, e posteriormente passaram por análise. ${ }^{2}$ Para a análise, foram escolhidos os temas mais frequentes nas narrativas, ou seja, as histórias em comum entre as entrevistadas e que apareceram como essenciais dentro da construção de uma identidade homoafetiva. Alguns temas estiveram presentes em praticamente todas as entrevistas, outros surgiram em algumas delas, mas todas as temáticas que foram analisadas estiveram presentes em pelo menos duas entrevistas.

\section{As entrevistas e as entrevistadas}

Para obtenção dos relatos, foram realizadas entrevistas narrativas individuais com sete mulheres que se identificam como lésbicas, com idade entre 24 e 30 anos e oriundas tanto de escolas públicas quanto de escolas particulares do estado do Rio Grande do Sul. Para a condução das entrevistas, foi elaborado um roteiro com o intuito de trazer à tona as histórias e as percepções dessas mulheres marcadas pela memória escolar. No entanto, as entrevistas não se restringiram ao roteiro, ou seja, no decorrer da conversa, foram adicionados e/ou excluídos diferentes questionamentos conforme a necessidade, o percurso e a especificidade de cada conversa.

A identidade das entrevistadas foi preservada, os nomes apresentados são fictícios. Todas foram informadas com detalhes sobre os objetivos, o conteúdo da pesquisa e a utilização das narrativas dentro do trabalho e oficializaram sua concordância a partir da assinatura do Termo de Consentimento Livre e Esclarecido (TCLE). A escolha das entrevistadas foi feita por conveniência, ou seja, foram escolhidas mulheres prontamente acessíveis em participar da pesquisa. As entrevistadas são pertencentes a um círculo afetivo, vínculo que pôde garantir segurança, acolhimento, e conforto na coleta dos relatos. A aproximação afetiva se mostrou bastante positiva no decorrer das entrevistas, pois propiciou abertura e intimidade para que as memórias fossem revividas e relatadas em um espaço de escuta sensível e acolhedora. No Quadro 1 está descrita a relação das entrevistadas juntamente com alguns dados relacionados ao percurso escolar.

\footnotetext{
${ }^{2}$ As entrevistas foram gravadas com um celular do tipo smartphone por meio do aplicativo Gravador de Voz (Quality apps, 2018). Posteriormente, as entrevistas foram tratadas, quando necessário, através do software Audacity (The Audacity Team, 2018). Após o tratamento, que envolveu, principalmente, a amplificação dos áudios, as entrevistas foram transcritas com auxilio de ferramentas de ditado e transcrição, tais como Transcribe e Dictation. io, e do software InqScribe (Inquirium LLC, 2018). Depois de transcritos, os arquivos de texto foram analisados com auxilio do software NVivo (QSR International, 2018).
} 
Quadro 1: Relação das entrevistadas e informações sobre o percurso escolar

\begin{tabular}{|c|c|c|c|c|}
\hline Nome & Idade & Ano de conclusão & Tipo de rede & Perfil de cidade \\
\hline Bia & 26 & 2009 & Privada & Interior \\
\hline Nanda & 24 & 2011 & Pública & Região metropolitana \\
\hline Liana & 30 & 2004 & Pública & Interior \\
\hline Márcia & 28 & 2007 & Majoritariamente* privada & Majoritariamente* interior \\
\hline Lara & 25 & 2010 & Privada & Capital \\
\hline Brenda & 29 & 2008 & Majoritariamente* pública & Interior \\
\hline Josi & 27 & 2008 & Majoritariamente* pública & Interior \\
\hline
\end{tabular}

*O termo 'majoritariamente' significa que a entrevistada frequentou as duas redes ou cidades, estando, na maior parte do tempo, na rede/cidade apontada no campo.

\#PraTodoMundoVer Quadro constando a relação das entrevistadas com os seguintes itens: nome, idade, ano de conclusão da escola, tipo de rede e perfil de cidade. Bia, 26 anos, conclusão em 2009, rede privada, interior. Nanda, 24 anos, conclusão em 201 1, rede pública, região metropolitana. Liana, 30 anos, conclusão em 2004, rede pública, interior. Márcia, 28 anos, conclusão em 2007, majoritariamente rede privada, majoritariamente interior. Lara, 25 anos, conclusão em 2010, rede privada, capital. Brenda, 29 anos, conclusão em 2008, majoritariamente rede pública, interior. Josi, 27 anos, conclusão em 2008, rede majoritariamente pública, interior.

Fonte: elaborado pelas autoras.

\section{Análises e discussão}

\section{A sexualidade no ambiente escolar}

Com o objetivo de introduzir a questão da iniciação da sexualidade, primeiramente falaremos sobre a adolescência como uma categoria social. A adolescência como período de transição entre a juventude e a vida adulta é um conceito relativamente recente construído por diversos fatores, dentre os quais estão os biológicos e os sociais (Rosângela SOARES, 2000). Considerando aspectos biológicos, adolescentes passam por alterações fisiológicas relacionadas aos órgãos sexuais e à capacidade reprodutiva, motivos pelos quais se atribui a essa fase da vida o início dos desejos e atividades ligadas à sexualidade. A adolescência e a juventude, de forma mais ampla, são colocadas como o momento em que a experimentação da sexualidade possibilitará uma construção de identidade, assim como também são momentos decisivos para demarcação de diferenças de gênero. No entanto, as concepções que se moldaram acerca da cultura juvenil muitas vezes se configuram como formas de controle, estando, também, a sexualidade das(OS) adolescentes e jovens em constante vigilância (Mary CASTRO; Miriam ABRAMOVAY; Lorena SILVA, 2004).

A partir das narrativas, foi possível perceber como a escola possui, muitas vezes, um papel central na construção da sexualidade. O primeiro beijo e a socialização para a descoberta dos primeiros contatos físicos são aspectos que frequentemente apareceram como acontecimentos vividos na escola e com sujeitos envolvidos no contexto escolar.

Todas as minhas colegas estaram ficando com alguém. Lá pela sétima série, eu fiquei com uns dois colegas meus em festinha, quando começava a ir em festinha. Mas muito mais porque todo mundo tava ficando. (Bia).

Já tinha rolado muitos beijos em muitas meninas, crianças, coleguinhas. Só que meu primeiro beijo 'oficial' foi [com] um homem, e foi todo aquele circo, né. Atrás da escola. Eu quase morri de nervosa antes de tudo isso. Aí a gente foi, assim, ele veio dum canto, eu vim do outro e a gente se beijou. (Brenda).

O papel significativo da escola na iniciação e nas primeiras descobertas com relação à sexualidade pode ter relação com diversos fatores. Um deles seria a quantidade de tempo que a criança/adolescente passa na escola sendo, nesse espaço, onde ocorre a maior parte da socialização e da convivência com outros sujeitos da mesma faixa etária. Além disso, a infância e a adolescência são períodos cruciais para a descoberta sexual, já que nesses períodos ocorrem, respectivamente, os primeiros contatos com diferenças sexuais (ou seja, a percepção da diferenciação corporal entre meninos em meninas), com o corpo (próprio e do outro) e o reconhecimento como sujeitos sexuados (Ana Cláudia MAIA, 2014). Considerando esses aspectos, não é de se surpreender a frequência da menção ao espaço da escola como local e meio de início das primeiras trocas e descobertas da sexualidade. No entanto, a sexualidade juvenil está em constante vigilância dentro do espaço escolar. Maria Cristina Cavaleiro (2009) chama de "pedagogia dos hormônios" um dos fenômenos que explica o controle sobre a sexualidade juvenil na escola sob justificativa de uma suposta ebulição hormonal ocorrida na adolescência.A 
autora alerta que esse fenômeno, além de regular a sexualidade juvenil, representa um conjunto de concepções biologicistas comprometidas com a manutenção da sexualidade normativa associada linearmente à reprodução biológica.

Assim, o atravessamento da escola por pautas relacionadas à sexualidade é inevitável, pois são questões presentes e pulsantes nos corpos e mentes da juventude que frequenta a escola. Por mais que a sexualidade muitas vezes seja vista como um tema que deve permanecer restrito ao campo do privado, não devendo ser abordado em um contexto público como é a escola (Débora BRITZMANN, 1996; MORGADE, 2015), é um assunto que necessariamente irá adentrar a instituição escolar, cabendo a esta o acolhimento receptivo, de maneira a apresentar uma orientação efetiva aos sujeitos quanto às vivências relativas à iniciação sexual e à construção de identidades.

\section{A aproximação de uma identidade homoafetiva}

Em relação aos primeiros passos em direção ao encontro de uma identidade homossexual, percebeu-se que a escola adotou papéis diferentes na vida de cada entrevistada, sendo menos universal nesse percurso do que na iniciação da sexualidade. Apareceram relatos de experiências e explorações corporais com outras meninas, colegas de escola ou não, ainda na infância. Entretanto, enquanto algumas conseguiam perceber com mais clareza algum tipo de interesse sexual-afetivo por mulheres ainda no período escolar, para outras, essas descobertas vieram mais tarde, quando já não mais frequentavam a escola.

Eu brincava, eu lembro muito de uma colega. [...] Eu ia na casa dela e em certos momentos, a gente tinha brincadeiras que acabavam, sabe... Só que na nossa cabeça não era uma coisa sexualizada ou enfim. Era uma exploração de duas meninas. [...] Mas, no fundo, eu tenho certeza que foi reprimido. [...] Eu só saí do armário depois da faculdade, então não teve nunca nada físico, assim, atos. Mas existia atração, com certeza. (Liana).

Eu sempre era a criança que puxava esse tipo de brincadeira, sempre era protagonista, sempre queria e forçava um pouco essa relação com as minhas amiguinhas, sempre queria beijar, queria tá perto, queria encostar, queria pegar na 'xereca'. [... E] a aí, aconteceu muitas e muitas vezes. Dentro da escola, fora da escola, com as minhas primas. (Brenda).

Na sétima série eu já tinha plena noção que eu sentia atração física pelas meninas e tal. Uma coisa que eu não sabia muito bem o que era, assim. E fui ficar com a primeira menina no primeiro ano já, do Ensino Médio. E aí foi uma coisa que descobri outras meninas que também curtiam meninas, e aí a gente meio que se descobriu junto, conversou sobre isso junto. (Josi).

Eu beijei uma amiga minha a primeira vez que eu beijei menina. Que foi no verdade ou consequência', ${ }^{3}$ na casa duns amigos da escola. [...] E achei muito bom! E depois eu falei com ela, mais tarde, anos depois. E ela disse que não tinha achado legal, eu disse 'eu já achei maravilhoso'. Talvez isso já era uma diferença, assim, que aí era mais evidente. (Lara).

A partir dos relatos, foi possível perceber que, para algumas meninas, esse percurso foi bem mais lento do que para outras, situação que pode ser relacionada a alguns fatores. Primeiro, a atuação forte da heterossexualidade compulsória na vida dessas mulheres que, em boa parte da iniciação sexual, acabaram por exercer a sexualidade com pares masculinos mesmo que não fosse uma experiência agradável ou prazerosa, como abordaremos com mais detalhes a seguir. Além disso, destacamos a questão das amizades entre mulheres e a menor 'vigilância' às quais as meninas estão submetidas no que tange às relações de amizade e ao carinho com outras meninas. A amizade, a troca de afeto e a curiosidade de desejos entre meninas são aceitas e esperadas, facilitando possibilidades de experimentação. Para os meninos, as trocas carinhosas envolvendo contato físico são muito mais vigiadas e problematizadas, já que o afeto entre meninos não se enquadra na masculinidade cultuada (CAVALEIRO, 2009), estando em constante atenção exatamente por sinalizarem, aos olhos do observador, um possível sinal de homoafetividade. Essa questão remete a uma cena presenciada por uma das autoras anos atrás, em um ônibus, quando uma avó viajava com seus dois netos. Em algum momento da viagem, os meninos trocaram carinhos, como abraços e beijos, sendo, imediatamente, repreendidos pela avó, que afirmou que meninos não podiam se abraçar ou se beijar daquele jeito. Ou seja, mesmo o fato de os meninos em questão possivelmente serem irmãos ou primos, não os absteve da vigilância e da repressão às atitudes carinhosas. Entre as meninas, esse tipo de troca física não necessariamente é visto como sexual, o que poderia mascarar ou atrasar a descoberta da homossexualidade, até mesmo para as próprias envolvidas. Como algumas delas pontuaram, a interpretação de atos de carinhos já gerava certo desconforto e algum tipo de sentimento 'diferente', o que elas veem, hoje, como primeiros indícios de um desejo homoafetivo que, na época, não era reconhecido.

3 'Verdade ou consequência' é um tipo de jogo no qual uma pessoa interrogada pode escolher entre verdade (responder uma pergunta) ou consequência (cumprir alguma tarefa designada pelo grupo). No caso da entrevistada, o beijo na amiga seria a 'consequência' definida pelo jogo. 
Além disso, Borillo (2009) e Cavaleiro (2009) alertam que a menor perseguição às lésbicas (quando em comparação aos homens gays) não pode ser interpretada como maior tolerância, pelo contrário, seria um reflexo da misoginia que, ao fazer da sexualidade feminina um objeto do desejo masculino, torna impensáveis as relações erótico-afetivas entre mulheres.

Para as outras meninas que já percebiam e vivenciavam a experiência homossexual durante a escola, algumas estratégias foram citadas para que fosse possível a vivência dessas experiências afetivas diferentes do padrão estabelecido na escola.

Desde o início, das primeiras gurias que eu fiquei, já acabei me aproximando mais com essas gurias. E a gente ficou super amigas e se acompanhou, e elas também sempre apoiaram. [...] Fugir da cidade pra que isso não fosse descoberto e conseguir, também, de alguma forma viver isso. (Josi).

Eu adotei a identidade bissexual, que era modinha. Entre as gurias, só isso que podia. E era um pouco cool, já, beijar gurias. Tinha aquela musiquinha da Katy Perry, I kissed a girl. [...] Eu acho que eu ficava bastante com as gurias e com as pessoas desconstruídas, porque eu me sentia muito ofendida, profundamente ofendida, com pessoas de mente estreita e homofóbica, preconceituosas no geral. (Lara).

Eu conversava com algumas pessoas, mas eu escondi durante muito tempo. Eu tinha várias amigas héteros da época do colégio, de Ensino Fundamental, e que eu achei que elas não iam aceitar. E eu fui embora da vida delas. Fui embora da vida de muitas pessoas sem nem falar. [...] Eu tinha receio dos outros, tipo 'eu vou perder pessoas, as pessoas não vão me aceitar'. (Márcia).

Com essas narrativas, percebe-se o quanto as interações são importantes nesse momento de descoberta. A interação com as amizades pode representar tanto um refúgio positivo, quando se têm amigas e grupos próximos que servem como fonte de apoio e diálogo, quanto negativo, representado no medo de perder as pessoas próximas por conta de uma possível não aceitação. Nessas situações, também fica claro o papel da escola para além de um espaço de formação educativa, mas também como um espaço de socialização, no qual é possível buscar e manter relações de amizade, interações entre pares e a procura por grupos semelhantes. Conforme explica Juarez Dayrell (2007), a sociabilidade é uma condição juvenil, tanto nos espaços de lazer e diversão quanto nos espaços institucionais como a escola. O autor coloca a turma de amigos como uma referência na trajetória da juventude, com quem se conversa, se faz programas e se cria um 'eu' e um 'nós' distintos. A sociabilidade representa uma resposta às necessidades de comunicação, de autonomia, de trocas afetivas e de identidade da juventude. Considerando, também, a totalidade de tempo que a juventude passa dentro do espaço escolar e todas as relações que nascem dentro da instituição, é possível perceber o caráter da escola como um agente socializador, que possibilitou às entrevistadas estratégias de acolhimento ou sentimento de culpa durante o processo de descoberta da homoafetividade. Sobre o sentimento de culpa e o medo da perda, Cavaleiro (2009) registra a existência de uma discriminação antecipada ou temida, que confina experiências homossexuais no campo do privado. Assim, é introjetado o que não se deve expressar dentro das interações sociais, impregnando de tensões aquilo que é escondido e contribuindo para o isolamento e para a estigmatização das sexualidades não normativas.

\section{A violência de gênero e a LGBTfobia}

Ainda dialogando com a questão da descoberta e do reconhecimento de um desejo homoafetivo, começam a aparecer as questões relacionadas às situações de violência de gênero. Um aspecto significativo nas entrevistas leva a entender que, em alguns casos, o apontamento externo se antecipa ao autorreconhecimento. Para muitas meninas, situações de julgamento da sua sexualidade por parte de outras pessoas vieram antes delas mesmas se perceberem, se entenderem ou até mesmo de entenderem o que significava ser lésbica. As situações apareceram tanto dentro quanto fora da escola, e dão indícios fortes sobre a ałuação de estereótipos de gênero como base para julgamentos, repressão e discriminação.

Isso sempre foi muito apontado pra mim, todo mundo falava sobre isso, sabe, me chamava de sapatão, dizia que eu parecia um guri. E eu não ficava olhando pras gurias, não tinha interesse, e ao mesmo tempo nem com guri também. [...] Isso partia muito mais das outras pessoas do que de mim. (Bia).

Aprendi a jogar bola com os guris, com meus irmãos, sempre tive a vida de guri, se for comparar. [...] Eu era uma referência que parecia um menino. Mas isso não rolou no colégio, rolou na rua onde eu cresci e a gente brincava. Eu tinha 11 anos e um gurizinho falou 'tu até machorra é', e eu não sabia nem o que significava isso. (Nanda).

Como se pode perceber nos relatos, o fato de as meninas apresentarem comportamentos ou estilos relacionados aos gostos masculinos (como gostar de jogar futebol ou outras atividades físicas, utilizar vestimentas mais largas e mais confortáveis, não se identificar com padrões de 
comportamento relacionados ao feminino, não demonstrar interesse por meninos na escola) foi crucial para que elas tivessem a sua sexualidade julgada antes mesmo de perceberem seus desejos como desviantes da norma heteronormativa.

Assim, podemos perceber que as violências sofridas e presenciadas no contexto escolar estão muito pautadas em questões relativas ao gênero, ou seja, não era necessário perceber que as meninas se sentiam atraídas por outras meninas para que elas fossem lidas como homossexuais, bastou, apenas, que elas adotassem comportamentos um pouco diferentes daqueles esperados para as mulheres. Essas situações também incluem sentimentos de desconforto e autorrepressão, momentos em que a própria entrevistada se percebia como diferente, com sensações de não pertencimento aos grupos das meninas.

O que eu tenho bem marcado [...] é com relação ao estereótipo. Eu sempre fui chamada de piazinho, de guri. E acho que a questão de eu sempre praticar esporte, [...] jogar futebol. A parte do esporte, junto com o meu jeito, assim, de me portar e me vestir, foi uma coisa que sempre me incomodou. (Liana).

Uma lembrança que eu tenho mais forte é de quando eu era bem criança, estava no pré da primeira série, que eu jogava bola com os guris. E aí sempre jogava o mesmo time. E esse time, resolveram, no verão, que era o time sem camisa, aí eu queria jogar sem camisa também. [...] Vinha professora mandar botar camiseta, daí eu não queria botar camiseta, tirava a camiseta, aí, foi, até que chamaram minha mãe na escola. [...]. E aí foi decidido, então, que o nosso time ia ser com camiseta. E aí, terminou meio que por aí, goela abaixo, que eu não podia fazer isso, que eu não podia mostrar os peitos, que eu era uma menina e que eu não podia. (Josi).

Tinha o casaco das gurias e o casaco os guris, que era tipo casaco de esporte, assim. E o casaco das gurias era de malha mais justinho. [...] E quando a minha mãe foi comprar uniforme pra mim eu fui provar e disse 'eu não quero usar essas coisas que me apertam, eu quero usar calça de tactel'. Então, quando eu cheguei na escola de calça de tactel, All Star e um casaco fechado, isso já foi o primeiro momento em que as pessoas me olharam, sabe. Tipo 'ah, ela se veste como guri', no uniforme da escola. Porque eu era a única guria que usava aquilo. (Bia).

Ainda trazendo os relatos, gostaríamos de destacar o relato a seguir, que traz uma situação de discriminação sofrida pela entrevistada que acabou resultando em agressão física.

Quando começou a esquentar [...] a gente foi pra aula de Educação Física, e eu tava de [calça] corsário [...], e eu tinha pelo nas pernas. E as minhas colegas todas, com 12 anos de idade, faziam as unhas e depilavam as pernas com cera. [...] E elas criaram uma música que falava das minhas pernas e das roupas que eu usava. E quando eu fui sentar pra descansar, elas vieram em grupo [...] e pararam na minha frente e começaram a cantar essa música. [.. .] E daí, eu pedi pra parar e elas não pararam e começaram a rir e começaram a dizer que eu parecia um guri e cantavam a música de novo, tipo 'guria que tem pelo nas pernas parece um guri, lá lá lá.' E eu pedindo pra parar e o professor não fez nada, tipo 'hahaha', deu as costas. [...] E eu respondi com uma agressão física porque eu sabia que eu tinha mais força física do que elas e que essa era a forma que eu tinha de me defender. (Bia).

A partir dos relatos, pode-se perceber o quanto foi influente nas vivências dessas mulheres as questões de gênero e o quanto o menor desvio do que se esperava de uma menina tornava-as suscetíveis a situações de constrangimento e violência. São demonstrações da maneira pela qual as mulheres homossexuais são atravessadas, concomitantemente, por violências de gênero combinadas com reações de cunho lesbofóbico. Sobre as questões relacionadas ao gênero e à leitura à qual as mulheres lésbicas estão submetidas, pode-se perceber o corpo como um importante marcador. Louro (2011) aponta o corpo como principal referência que ancora a identidade, sendo muito forte o investimento nos corpos como construções de imposições culturais, numa tentativa constante de adequá-los a conceitos estéticos e morais. Aprendemos a classificar os sujeitos pelas formas de apresentação e expressividade corporal que adotam, decodificando esses sinais a partir dos conceitos que são criados e impostos como norma. Nos processos de vigilância de gênero, construções corporais que possam fugir do que é esperado para um determinado gênero são constantemente monitoradas e, não raramente, rejeitadas e reduzidas. E é exatamente neste terror em relação à perda de gênero que surge a LGBTfobia, corpos considerados desviantes das normas esperadas para o seu gênero são submetidos a policiamentos e censuras de modo a regular, também, as manifestações de sexualidade (LOURO, 1999). Pensando por esse viés é mais fácil entender os relatos apresentados pelas entrevistadas: o mínimo distanciamento de um padrão corporal e de comportamento ligado ao feminino (e a consequente aproximação daquilo que era considerado um padrão masculino) representou um alerta de vigilância desses corpos, que foram, muitas vezes, inferiorizados e ridicularizados com o intuito de censurar manifestações de gênero e de uma possível sexualidade desviante da norma.

Adicionalmente, a violência e a regulação de gênero são apontadas por Paulo Rogério Neves (2008) como fatores responsáveis por violências físicas e brigas entre meninas na escola, concordando com a situação envolvendo agressão física relatada pela entrevistada. Segundo 
o autor, a escola é um espaço onde assuntos privados se tornam públicos, gerando brigas e agressões físicas como forma de restituição da privacidade e rompimento violento com um modelo vigente, principalmente quando os canais de comunicação dentro da escola são ineficientes.

Como resultado dos processos normatizadores dentro da escola, percebemos grande frequência de situações de agressões de cunho LGBTfóbico. Nas situações trazidas pelas entrevistadas, foi possível resgatar tanto casos de violências sofridas por elas mesmas, como situações envolvendo outras pessoas LGBTs. Dentro do contexto da pesquisa, percebemos que as violências estiveram mais presentes em escolas privadas, locais onde prevalecem, também, questões econômicas e onde alunas(os) estão mais atravessadas(os) por padronizações estéticas. Além disso, escolas privadas geralmente são espaços menores, onde a comunidade escolar vive mais próxima e sofre mais interferência de opiniões e julgamentos. Escolas públicas, ao contrário, apareceram como espaços mais abertos, não totalmente livres de situações de LGBTfobia, mas onde estudantes podiam se expressar com mais liberdade. ${ }^{4}$

Por todo tempo chamavam de sapatão, diziam que eu queria pegar as gurias da escola, eu me lembro de pessoas que, quando me viam entrando no banheiro, diziam que não iam entrar no banheiro porque eu tava lá. [...] E de dizer que o meu banheiro tinha que ser o banheiro masculino, sabe. (Bia).

A única vez que eu me lembro de um professor falar sobre gays na sala de aula foi esse professor de Química fazendo piada. Em sala de aula, durante uma aula. [...] Não se falava sobre isso lá na escola. (Bia).

Enquanto eu ainda estava no Ensino Médio, rolou vários comentários, que a galera sabia. [...] Isso de comentarem pras mães das gurias que eram super minhas amigas, que eu namorava as gurias. [...] E era sempre bem tenso, porque sempre muito na maldade, sabe. (Josi).

Não era gay, era bichinha, 'aquele cara é uma bicha, viado, olha lá'. Os guris riam muito, apontavam, tu via o sofrimento da outra pessoa. Pras meninas também, quando uma sapatão era identificada, o que acontecia? 'Feia, ela é feia, ela nunca vai ter ninguém, essa mina é bizarra'. E isso tu vai sentindo um pavor de que as pessoas apontem pra ti. Sempre foi uma coisa muito complicada as pessoas apontarem pra mim. (Márcia).

As violências relatadas são de diversos tipos: chacotas, agressões verbais, bullying, e praticadas, inclusive, por professoras(es). A LGBTfobia está fortemente relacionada com o processo de naturalização de regras determinadas arbitrariamente quanto a expressões de gênero e sexualidade, que geram, como consequência, uma rejeição a todas as expressões de sexualidade que fogem da ótica heterocêntrica. Assim, vemos que a escola não só é incapaz de lidar com a diversidade como, muitas vezes, é um espaço onde violências de cunho LGBTfóbico são ensinadas e consentidas.

Peres (201 1), em concordância com os relatos das entrevistadas, registra que as práticas de bullying de cunho LGBTfóbico variam entre formas sutis (piadas, risadas e comentários irônicos) até formas mais graves que levam a situações de agressão física, perseguição, humilhação e violação. Quando vêm em coro, as consequências dessas práticas se potencializam (PRADO; RIBEIRO, 2015). Esses autores apontam, ainda, que presenciar situações em que o 'outro' sofre essas perseguições também constitui uma experiência de regulação de corpos homossexuais, restringindo as possibilidades de se reconhecer positivamente em uma identidade estigmatizada. Corpos que não reproduzem a lógica ordenada entre sexo biológico e orientação sexual são frequentemente condenados à marginalidade e à despotencialização dentro da escola. Esse estudo, que também escutou a fala de jovens sujeitos dessas violências, retratou, ainda, situações nas quais agentes pedagógicos se abstêm da problematização dessas discriminações, camuflando a origem do conflito ao tratar como uma briga comum e condenando a vítima às mesmas sanções direcionadas ao agressor, deixando de apontar as especificidades que originam essas violências. Cláudia Vianna e Maria Cristina Cavaleiro (2016) também trazem relatos de adolescentes lésbicas estudantes de escolas públicas e demonstram a atuação de mecanismos de controle da sexualidade das meninas. O trabalho registra um controle que, muitas vezes, se traveste de cuidado, proibindo demonstrações de afeto para evitar um possível 'problema' para as alunas e para a escola. No estudo em questão, a escola chegou ao máximo de solicitar que essas alunas não mais frequentassem o ambiente escolar, evidenciando a violência lesbofóbica como potencial causadora de evasão escolar. Assim, as autoras apontam para um fenômeno de controle invisível da liberdade de expressão, alertando que esse controle representa uma violação dos direitos humanos (o direito à não discriminação). A violência de cunho LGBTfóbico também representa uma interferência negativa na construção de identidades sexuais. Junqueira (2013) traça uma relação direta entre a "pedagogia do insulto" e a "pedagogia do armário" dentro da

${ }^{4}$ A comparação entre escolas públicas e particulares não estava entre os objetivos da pesquisa. No entanto, os relatos trouxeram algumas pistas que puderam ser observadas, apontando para essas diferenças. 
escola, atestando que as práticas de controle de gênero e da sexualidade condenam pessoas não heterossexuais a situações de injúria, insultos e discriminações, o que pode ocasionar processos de silenciamento, ocultamento, marginalização e exclusão de identidades não normativas.

Outro retrato (ou consequência) das normas impostas às meninas na vivência da sua sexualidade muito presente nas entrevistas é a heterossexualidade compulsória. Para entender esse fator, levamos em consideração o determinismo pressuposto de que um sexo biológico teria estabelecido como objeto de desejo necessariamente o sexo oposto, norma que exerce forte pressão ao guiar as práticas afetivas e sexuais dos sujeitos. Neste trabalho, a força da heterossexualidade compulsória não só foi presente como se mostrou danosa às entrevistadas, a partir de relatos de experiências afetivas/sexuais infelizes para as meninas, no sentido de estarem se submetendo a situações às quais elas não desejavam ou de fazerem tentativas de relações heterossexuais que não refletiam os desejos sentidos na época.

Eu pegava os boys. Mas quando eu comecei a transar com boy foi uma questão muito grande. Porque eu não conseguia! No início, sim, sentia prazer porque, né, tu tá beijando alguém, alguém tá te apertando. [...] Mas transar com boy sempre foi uma questão pra mim. Eu 'transei' com uns sete caras na vida, mas, dos sete, seis eu parei na metade. (Nanda).

No me colocar como heterossexual eu me colocava em situações que eu não queria de verdade. Tipo, de ficar com meninos, de transar com meninos. Teve momentos que, sim, que eu curti estar com eles e transar etc. Mas foi muito pouco perto das tantas vezes que eu realmente não precisava ter feito, não queria. Mas fiz porque eu queria continuar me colocando, me encaixando, justamente pra não sofrer com todos os preconceitos. (Liana).

Eu já me escondia muito, e no outro dia me senti muito mal, eu me sentia culpada, não conseguia me olhar no espelho. Uma vez eu transei com um cara e, meu Deus! [...] Quando eu acordei eu fiquei mal, fiquei pensando 'meu Deus, por que eu fiz isso, eu sou uma ridícula', sendo que é uma coisa normal. Qualquer pessoa hétero faria isso normalmente. E eu me sentia muito mal, muito arrependida. (Márcia).

A partir desses relatos, percebemos que, para essas mulheres, o desconforto ao tentar se enquadrar em uma vida heterossexual foi mais uma das violências às quais elas foram submetidas nos momentos iniciais de descoberta da sexualidade. Por mais que o início da descoberta sexual seja um momento de experimentação, a repulsa às experiências heteronormativas já existia de alguma forma, mas o sentimento de desconforto não foi suficiente para que elas recusassem tais relações. É algo bastante simbólico no que tange à questão da lesbofobia, pois, para as mulheres, a questão de renegar relações heteronormativas também representa uma insubmissão ao masculino e à função feminina de reprodução, características muito sustentadas dentro do contexto patriarcal. Assim, a relação heterossexual se configura em uma pedra fundamental do sistema de dominação das mulheres. As forças do casamento e da orientação sexual voltada aos homens são apresentadas como componentes naturais e inevitáveis na vida das mulheres mesmo quando opressivas e não satisfatórias. Isso leva as mulheres a aceitarem condições degradantes, como assédio e estupro, e a se submeterem a relações voltadas unicamente para a satisfação sexual masculina. A heterossexualidade compulsória como instituição política assegura o direito masculino ao acesso físico, econômico e emocional ao corpo feminino (Adrienne RICH, 2010), imposta por meio da força, do controle e de violências físicas e simbólicas (Jules FALQUET, 2012). Os meios de convencimento e reiteração estão presentes desde cedo na vida das mulheres, como nas brincadeiras de boneca, nos contos de fada e na romantização das cerimônias nupciais (RICH, 2010; Tânia SWAIN, 2010). E, a partir dos relatos, evidenciamos como esse sistema é poderoso ao guiar os nossos corpos, pois, mesmo percebendo que aquelas relações não são agradáveis de serem vividas, ainda houve a insistência em vivê-las. A ruptura dessa norma se configura quase como inconcebível na construção sexual das mulheres.

\section{A sexualidade no currículo escolar}

Quanto ao currículo, todas as entrevistadas relataram aspectos semelhantes com relação aos conteúdos aprendidos na escola: a normatividade heterossexual impera e o conteúdo sempre esteve restrito ao sexo como risco, abordando apenas a prevenção de gravidez, com métodos contraceptivos, e de Infecções Sexualmente Transmissíveis (IST). Elas apontaram, também, as aulas de Ciências e Biologia como os únicos espaços em que existia algum tipo de abordagem em conjunto com temas relacionados aos órgãos e sistemas do corpo humano.

Eu lembro da coisa ser muito hétero, sempre. Desde aprender sobre o sexo, de ter isso, tipo, um cara vai transar contigo. [...] Era meio que dado assim: 'você é menina, você tem um buraquinho, o menininho tem um caminhão pra colocar na sua garagem'. [.. . ] Não existia nada além disso. (Nanda).

Reprodução, órgãos reprodutores, não como órgãos, enfim, sexuais, necessariamente. [...] Tudo dentro daquela coisa dos livros e figurinhas, homem, mulher, e aí, isso. Pênis, vagina, filho, enfim. 
[...] Nenhum professor entrou muito na parte mais de gênero, identidade, enfim, sexualidade, mesmo. (Liana).

Anatomia feminina, masculina. E reprodução, a questão de DST5, a gente teve sobre DSTs, uso de preservativo, de método contraceptivo, pílula, DIU. [...] Gravidez, gravidez na adolescência. [...] Eu lembro muito de cursos, de rolê de saúde, de ir pro colégio e levar camisinha, e falar sobre método contraceptivo, sobre a AIDS, sobre DST. [...] Sobre sexualidade, não. (Josi).

Os temas abordados em aula e trazidos nas narrativas concordam com a expectativa e com a atual e limitada abordagem de sexualidade na escola. Os anos 1980 foram marcados pelo crescimento do HIV e por maior aproximação da abordagem de ISTs. A gravidez na adolescência também ganhou destaque e atenção durante os anos 1990, sendo apenas essas duas questões absorvidas pelos currículos, trazidas juntamente com os estudos sobre a fisiologia e anatomia do corpo humano nas aulas de Ciências e Biologia. No entanto, abordagens que dialogassem com questões de gênero, identidades, orientação sexual e uma educação sexual baseada na diversidade não chegaram à escola, conforme os relatos das entrevistadas.

Mariana Gutierres (2015), analisando um dos principais livros didáticos utilizados por docentes de Biologia, traz diversas questões expostas nesse material que resumem como é abordada a questão da sexualidade na escola. É naturalizado que a reprodução humana é a única forma de viver a sexualidade, mostrando a função dos órgãos sexuais somente a partir da sua contribuição para a reprodução. Pensando sob essa ótica, uma ideia fica bastante clara: refletindo a sexualidade somente pelo recorte da reprodução, qualquer tipo de vivência homossexual fica fora dessa discussão. Além disso, a pesquisadora aponta como essa abordagem está a serviço da heterossexualidade e traz exemplos de frases do livro didático, como: "Vagina: estrutura que recebe o pênis durante a relação sexual e serve de canal de saída para o fluxo menstrual e para o bebê no momento do parto natural". Essa afirmativa coloca o corpo da mulher representado com submissão e passividade, retira o seu protagonismo durante a relação sexual e anula qualquer tipo de relação que não tenha o objetivo de reprodução ou que não envolva a presença de um pênis. São questões que concordam com aquilo que é exposto por Junqueira $(2010,2013)$, que aponta o currículo como um artefato político e, assim, uma produção cultural e discursiva impregnada de heteronormatividade. Além disso, percebe-se que é uma abordagem de sexualidade pautada como risco, na qual os únicos aspectos que interessam dizem respeito às maneiras de se evitar gravidez e ISTs. São demandas tratadas como problema de saúde sexual e reprodutiva, que buscam o controle dos corpos e dos comportamentos dos indivíduos. Tratase a sexualidade como perigo, como passível de doença, ou seja, ao mesmo tempo que é abordada, também não é recomendada. Junta-se a isso o processo descrito por Louro (1999), no qual cabe à escola o equilíbrio entre o incentivo da normalidade sexual e o desafio de contê-la. Ou seja, embora existam processos claros de normatização, existe também um investimento forte em manter a 'inocência' das(os) alunas(os) para que possam adiar a sexualidade para a vida adulta. Nesse processo, redobra-se a vigilância a todas(os) aquelas(es) que se atrevem a expressar a sua sexualidade, sendo, estas(es), muitas vezes estigmatizadas(os) como desviantes do comportamento esperado. Para aquelas(es) que percebem seus desejos desviantes da heteronormatividade, as coisas se complicam ainda mais, restando o silêncio, a dissimulação ou a segregação, estando a produção da heterossexualidade diretamente relacionada à rejeição da homossexualidade.

As abordagens de sexualidade com enfoque na prevenção da gravidez foram citadas por todas as entrevistadas. Considerando que a relação sexual entre homens ou entre mulheres não leva a esse risco, essa abordagem também contribui com a invisibilidade das questões ligadas ao público LGBT. A heteronormalização do sexo acaba, também, por contribuir para a vulnerabilidade das pessoas LGBTs frente às transmissões de ISTs (PRADO; RIBEIRO, 2015). Nesse contexto, apresenta-se uma desvantagem com relação às mulheres lésbicas quando em comparação aos homens gays. A camisinha masculina, por ser um dos mais difundidos métodos de sexo seguro, é sempre citada, e isso acaba contemplando, também, relações sexuais com penetração entre homens. Em contraposição, os métodos contraceptivos tradicionais não contemplam o sexo entre mulheres, e é importante mencionar que não há nenhum método de prevenção popularizado voltado às mulheres homossexuais, situações que acabam por negligenciar o cuidado e a segurança no sexo lésbico. ${ }^{6}$

Ainda considerando o apagamento dentro do currículo escolar, as entrevistadas apontaram como a falta de debate sobre sexualidade contribuiu para a própria invisibilidade, relatando que

\footnotetext{
${ }_{5}^{5}$ Desde 2016 o Departamento de Vigilância, Prevenção e Controle das IST, do HIV/aids e das Hepatites Virais passou a usar a nomenclatura Infecções Sexualmente Transmissíveis (IST) no lugar de Doenças Sexualmente Transmissíveis (DST). No entanto, o termo apareceu com a nomenclatura anterior em algumas citações das entrevistas.

${ }^{6} \mathrm{~A}$ adoção de métodos de prevenção no sexo entre mulheres é rara e sua necessidade é pouco disseminada. Pesquisas relacionadas às ISTs em mulheres lésbicas são escassas e a falta de acolhimento e de orientações adequadas por parte dos profissionais de saúde também são empecilhos para a saúde sexual de mulheres lésbicas.
} 
as próprias descobertas e vivências poderiam ter sido diferentes se houvesse uma referência ao tema dentro da escola.

Tem a ver com o fato de eu reprimir tanto porque também não conhecia, né. Não achava que era uma coisa normal porque não foi discutido na escola, obviamente. [...] Talvez se tivesse tido uma outra abordagem, enfim, eu tivesse saído do armário antes e evitado um monte de constrangimentos e coisas que eu não queria ter feito. (Liana).

Eu me lembro que todas as minhas amigas já tinham beijado alguém. Que ninguém realmente me interessava. Talvez se nessa época eu tivesse tido uma orientação, minha vida teria sido completamente diferente. Talvez eu nem tivesse transando com cara. [...] Eu passei por muita coisa que eu não deveria ter passado por não ter recebido uma orientação adequada. (Márcia).

Na verdade, eu achava que era só aquilo, assim. Que, tipo, eu que tava errada e que o que eu sentia que não existia e não podia existir. Tanto que 'se pá' era por isso também que eu tentava esconder. Mas eu lembro que não, nunca pensei 'nossa, não foi abordado', era meio que como se existisse um padrão e eu que não fizesse parte. (Josi).

Conforme Prado e Ribeiro (2015), não só o que está exposto no currículo sustenta a norma, mas os silenciamentos das expressões não hegemônicas e a omissão discursiva também exercem efeitos reguladores. O não dito também tem força na construção das subjetividades, dificultando que os jovens LGBTs aceitem, entendam e percebam o seu desejo sexual como possível e legítimo. Nesse sentido, Britzmann (1996) menciona que:

Consequentemente, as garotas não têm oportunidades de compreender e explorar os significados de seus corpos, os adolescentes gays e as adolescentes lésbicas não são reconhecidos/as e não têm, portanto, quaisquer oportunidades de explorar suas identidades e desejos ou até mesmo de buscar apoio institucional para intervir no processo de violência contra eles/elas. O que ocorre aqui é que estão sendo construídas identidades vulneráveis à vitimização sexual e está sendo produzido um discurso de proteção, no qual a ignorância circula como conhecimento. Os efeitos desse discurso, entretanto, não são vividos de forma uniforme. (BRITZMAN, 1996, p. 79).

Jorge Larrosa (1994) aponta que o ser humano é resultado de mecanismos em que as relações consigo mesmo são produzidas e mediadas através de condições de possibilidade. O autor assinala, então, os dispositivos pedagógicos como constitutivos da subjetividade, ou seja, eles fazem parte de uma série de mecanismos e locais nos quais se constituem e se transformam as experiências de si a partir daquilo que é narrado e mostrado como possível de ser vivido. Considerando esse cenário, podemos refletir sobre a importância de se pensar aquilo que é abordado no currículo para que se possibilite o autoconhecimento e o autorreconhecimento. A invisibilidade da diversidade sexual nos parâmetros abordados no currículo representa uma barreira no processo de pertencimento e de reconhecimento para as mulheres lésbicas que, não se vendo narradas dentro daquele currículo estruturado, também não conseguem enxergar a sua sexualidade como legítima e possível.

Assim, a ausência de temas relacionados à sexualidade que contemplem todas as identidades e orientações sexuais, além de contribuir para a hegemonia da heteronormatividade, representa a instituição da escola como um espaço de exclusão das mulheres lésbicas (e pessoas LGBTs no geral). O apagamento, além de tornar essas pessoas suscetíveis a riscos e desinformação, prejudica o reconhecimento e a construção de identidades.

\section{Consideraçōes finais}

Desenvolvendo esta pesquisa percebemos que o papel da escola dentro da constituição da identidade sexual dos sujeitos não é universal e é bastante diferente quando se aborda a questão das pessoas LGBTs. Para as entrevistadas, a escola não foi um local de acolhimento, representando, muitas vezes, um espaço onde a violência e a discriminação estiveram presentes, por questões relacionadas a estereótipos de gênero ou diretamente à sexualidade. A homoafetividade em nenhum dos casos expostos foi abordada nas temáticas relacionadas à sexualidade dentro do currículo escolar, contribuindo para a sua invisibilidade e dificultando a construção das identidades, dando espaço para situações bastante problemáticas como a autorrepressão e a heterossexualidade compulsória.

Embora a legislação preveja a abordagem de sexualidades e da educação sexual, na prática, o que vemos é que esses temas não conseguem adentrar os muros da escola. Há orientações que determinam que o currículo seja abordado com um enfoque cultural, porém, o que ainda impera é o viés biologizante que prejudica um olhar atento e acolhedor quanto à diversidade sexual. Tomaz Silva (201 1) aponta para a necessidade de uma pedagogia que busque para além de informações corretas sobre a sexualidade e tolerância da homossexualidade, e que questione todos os processos discursivos e institucionais, o correto e o incorreto, o moral e o imoral, o normal e o anormal. 
A questão que impera neste momento é que, quanto mais vemos a necessidade de inclusão da diversidade na instituição escolar, mais nos distanciamos do projeto de escola inclusiva. O contexto político brasileiro há muitos anos vem dificultando que as questões de gênero e sexualidade adentrem os muros da escola. Um claro exemplo é o embate político gerado pela proposta de distribuição de materiais pautando a LGBTfobia e a diversidade nas escolas. O material, produzido em parceria com o Ministério da Educação, foi vetado devido à atuação de grupos conservadores que distorceram de maneira brutal e ignorante o conteúdo do projeto, trazendo essas informações distorcidas ainda como força política no cenário eleitoral de 2018.

A escola como produtora de desigualdades se tornou ainda mais clara a partir das histórias dessas mulheres, que não se sentiam parte da hegemonia instituída dentro do espaço escolar. E o cenário atual da educação no Brasil é de mais retrocessos representados por um governo que, além de cortar verbas para a educação básica e superior, flerta com projetos de cerceamento da liberdade de expressão, de controle repressivo direcionado aos profissionais da educação e de ataques à educação crítica. Ou seja, a escola projetada pelo extremo conservadorismo que está no poder no Brasil é aquela que não apresenta espaço para temáticas que abordem a diversidade humana e a educação democrática.

Assim, apesar de conseguirmos apontar com clareza para as consequências de uma educação não inclusiva, parece ainda mais longe no horizonte um cenário no qual seja possível debater com abertura e objetividade os temas relacionados a gênero e sexualidade. E as pessoas não pertencentes à heteronormatividade hegemônica continuarão sendo altamente suscetíveis às consequências desse retrocesso. No entanto, a existência dessas pessoas também continuará representando grande fonte de resistência e de luta na construção de um cenário educativo e de uma sociedade na qual todos os direitos e todas as vivências sejam respeitadas e legitimadas.

\section{Referências}

ALTMANN, Helena; AYOUB, Eliana; AMARAL, Sílvia Cristina Franco. "Gênero na prática docente em Educação Física: 'meninas não gostam de suar, meninos são habilidosos ao jogar'?" Revista Estudos Feministas, Florianópolis, v. 19, n. 2, p. 491-501, maio/ago. 2011.

ANDRADE, Sandra Santos. "A entrevista narrativa ressignificada nas pesquisas educacionais pósestruturalistas". In: MEYER, Dagmar Estermann; PARAíSO, Marlucy Alves (Orgs.). Metodologias de pesquisas pós-críticas em educação. Belo Horizonte: Mazza Edições, 2012. p. 173-194.

ASSOCIAÇÃO BRASILEIRA DE LÉSBICAS, GAYS, BISSEXUAIS, TRAVESTIS E TRANSEXUAIS (ABGLT). Secretaria da Educação. Pesquisa nacional sobre o ambiente educacional no Brasil 2015: as experiências de adolescentes e jovens lésbicas, gays, bissexuais, travestis e transexuais em nossos ambientes educacionais. Curitiba: ABGLT, 2016.

BALESTRIN, Patrícia Abel; SOARES, Rosângela. "Gênero e sexualidade nas práticas educativas". Revista Retratos da Escola, Brasília, v. 9, n. 16, p. 47-61, jan./jun. 2015.

BORILLO, Daniel. "A homofobia". In: LIONÇO, Tatiana; DINIZ, Débora (Orgs.). Homofobia \& Educação: um desafio ao silêncio. Brasília: Letras Livres, 2009. p. 15-46.

BRASIL. Secretaria de Educação Básica. Parâmetros Curriculares Nacionais. Brasília, 1997.

BRITZMAN, Débora. "O que é esta coisa chamada amor: identidade homossexual, educação e currículo". Educação \& Realidade, v. 21, n. 1, p. 71-96, jan./jul. 1996.

CASTRO, Mary Garcia; ABRAMOVAY, Miriam; SILVA, Lorena Bernardete da. Juventudes e Sexualidade. Brasilia: UNESCO, 2004.

CAVALEIRO, Maria Cristina. Feminilidades homossexuais no ambiente escolar: ocultamentos e discriminações vividas por garotas. 2009. Doutorado (Programa de Pós-Graduação em Educação) - Faculdade de Educação da Universidade de São Paulo, São Paulo, SP, Brasil.

DAYRELL, Juarez. "A escola 'faz' as juventudes? Reflexões em torno da socialização juvenil". Educação \& Sociedade, Campinas, v. 28, n. 100 (Especial), p. 1 105-1128, out. 2007.

FALQUET, Jules. "Romper o tabu da heterossexualidade: contribuições da lesbianidade como movimento social e teoria política". Cadernos de Crítica Feminista, n. 5, p. 8-31, dez. 2012.

GUTIERRES, Mariana Ribeiro Gutierres. "BIO" sexualidade em discussão: o livro didático de Biologia produzindo verdades sobre o corpo. 2015. Especialização (Programa de Pós-Graduação em 
Educação) - Faculdade de Educação da Universidade Federal do Rio Grande do Sul, Porto Alegre, RS, Brasil.

JUNQUEIRA, Rogério Diniz. "Currículo heteronormativo e cotidiano escolar homofóbico". Revista Espaço do Currículo, João Pessoa, v. 2, n. 2, p. 208-230, mar. 2010.

JUNQUEIRA. Rogério Diniz. "Pedagogia do armário: a normatividade em ação". Revista Retratos da Escola, Brasília, v. 7, n. 13, p. 481-498, jul./dez. 2013.

LAQUEUR, Thomas. Inventando o sexo: corpo e gênero dos gregos a Freud. Rio de Janeiro: RelumeDumará, 2001.

LARROSA, Jorge. "Tecnologias do eu e educação". In: SILVA, Tomaz Tadeu da. O sujeito da educação. Petrópolis: Editora Vozes, 1994. p. 35-86.

LOURO, Guacira Lopes. Gênero, sexualidade e educação: uma perspectiva pós-estruturalista. Petrópolis: Editora Vozes, 2011.

LOURO, Guacira Lopes. "Pedagogias da Sexualidade". In: LOURO, Guacira Lopes et al. (Orgs.). O corpo educado: pedagogias da sexualidade. Belo Horizonte: Autêntica, 1999. p. 7-34.

MAIA, Ana Cláudia Bortolozzi. "Sexualidade e educação sexual". [Material Didático]. Programa Rede São Paulo de Formação Docente (REDEFOR): Educação Especial e Inclusiva. São Paulo, 2014. Disponível em: https://acervodigital.unesp.br/bitstream/unesp/155340/3/unesp-nead_reei 1 ee_d06_s03_texto02.pdf. Acesso em 22/03/2021.

NEVES, Paulo Rogério da Conceição. As meninas de agora estão piores que os meninos: gênero, conflito e violência na escola. 2008. Mestrado (Programa de Pós-Graduação em Educação) Faculdade de Educação da Universidade de São Paulo, São Paulo, SP, Brasil.

MORGADE, Graciela. "Políticas de educação sexual integral: saberes, práticas e corpos em tensão". Revista Retratos da Escola, Brasília, v. 9, n. 16, p. 63-71, jan./jun. 2015.

PADILHA, Lúcia Mara de Lima. "A criação da escola a partir da divisão social do trabalho". Publicatio UEPG: Ciências Humanas, Linguística, Letras e Artes. Ponta Grossa, v. 18, n. 1, p. 61-66, jan./jun. 2010.

PERES, Wiliam Siqueira. "Transfobias, lesbofobias e homofobias invisíveis: o que a escola tem com isso?" InterMeio: Revista do Programa de Pós-Graduação em Educação. Campo Grande, v. 17, n. 34, p. 154-176, jul./dez. 2011.

PRADO, Vagner Matias do; RIBEIRO, Arilda Inês Miranda. "Homofobia e educação sexual na escola: percepções de homossexuais no ensino médio". Revista Retratos da Escola, Brasília, v. 9, n. 16, p. 137-152, jan./jun. 2015.

RICH, Adrienne. "Heterossexualidade compulsória e existência lésbica". Bagoas - Estudos Gays: Gêneros e Sexualidades, v. 4, n. 5, p. 17-44, nov. 2010.

SILVA, Tomaz Tadeu da. Documentos de identidade: uma introdução às teorias do currículo. Belo Horizonte: Autêntica, 2011.

SOARES, Rosângela. "Adolescência: monstruosidade cultural?" Educação \& Realidade, Porto Alegre, v. 2, n. 25, p. 151-159, jul./dez. 2000.

SWAIN, Tânia Navarro. "Desfazendo o 'natural': a heterossexualidade compulsória e o continuum lesbiano". Bagoas - Estudos Gays: Gêneros e Sexualidades, v. 4, n. 5, p. 45-55, nov. 2010.

VIANNA, Cláudia; CAVALEIRO, Maria Cristina. "Lesbofobia e cotidiano escolar: controle invisível da liberdade de expressão". Revista Diversidade e Educação, v. 4, n. 7, p. 40-43, jan./jun. 2016.

Ana Laura Almeida (analaura.al@gmail.com) é bacharela e licenciada em Ciências Biológicas e mestre em Ecologia, todos os graus obtidos pela Universidade Federal do Rio Grande do Sul (UFRGS). Mulher lésbica interessada nas temáticas de gênero, sexualidade e LGBTQIAP+ fobia no contexto educacional. Educadora Social e Ambiental comprometida com a educação democrática e os direitos humanos.

Rosângela Rodrigues Soares (rosangela.soares@ufrgs.br) é mestre e doutora em Educação pela Universidade Federal do Rio Grande do Sul (UFRGS). Professora associada da 
Faculdade de Educação da UFRGS. Membro e pesquisadora do Grupo de Estudos em Educação e Relações de Gênero (GEERGE), atuando principalmente nos seguintes temas: formação de professores e culturas juvenis.

\section{COMO CITAR ESSE ARTIGO DE ACORDO COM AS NORMAS DA REVISTA}

ALMEIDA, Ana Laura; SOARES, Rosângela Rodrigues. "Narrativas de mulheres lésbicas sobre as vivências no cotidiano e no período escolar". Revista Estudos Feministas, Florianópolis, v. 29, n. 1, e57625, 2021.

\section{CONTRIBUIÇĀO DE AUTORIA}

Ana Laura Almeida: concepção, coleta e transcrição das entrevistas, análise dos dados, discussão de resultados, elaboração e redação do manuscrito.

Rosângela Rodrigues Soares: orientação da pesquisa, auxílio na análise dos dados e discussão de resultados, revisão do manuscrito.

\section{FINANCIAMENTO}

Não se aplica.

\section{CONSENTIMENTO DE USO DE IMAGEM}

Não se aplica

\section{APROVAÇĀO DE COMITÊ DE ÉTICA EM PESQUISA}

Não se aplica. O preenchimento do Termo de Consentimento Livre e Esclarecido foi suficiente para a realização do trabalho.

\section{CONFLITO DE INTERESSES}

Não se aplica.

\section{LICENÇA DE USO}

Este artigo está licenciado sob a Licença Creative Commons CC-BY 4.0 International. Com essa licença você pode compartilhar, adaptar, criar para qualquer fim, desde que atribua a autoria da obra.

\section{HISTÓRICO}

Recebido em 17/09/2019

Reapresentado em 13/10/2020

Aprovado em 06/1 1/2020 